\title{
Pragmatic justifications, realism and truth: How does the suggestion to justify coherent belief systems pragmatically relate to Brümmer's views?
}

It is a privilege to have been invited to contribute to analysing Vincent Brümmer's impressive oeuvre at the occasion of his $80^{\text {th }}$ birthday. Being the successor on his chair in the philosophy of religion at Utrecht University, I will focus on philosophical aspects of his work. In particular, I will zoom in on his considerations on truth.

After providing an overview of Brümmer's critique of coherentist and pragmatist definitions of truth (see section 1), I will make a suggestion on how coherentist and pragmatic criteria can be used alternatively (see section 2). The upshot will be an account of pragmatic justification. In section 3, I flesh out the consequences of this account for the issues of realism and truth. In section 4, I investigate how this account relates to Brümmer's views on the issues.

\section{BRÜMMER ON TRUTH}

\subsection{Brümmer's critique of coherentist and pragmatic theories of truth}

One of the intriguing features of Brümmer's comprehensive oeuvre is that it relates theoretical to applied considerations. The latter range over a number of issues crucial in the philosophy of religion, such as the function of prayer, the relationship between science and religion, the question whether secular accounts of love can function as a model for God's love, etc. The foundation of those applied considerations is laid in a number of publications on theoretical issues, chief among them the book 'Theology and Philosophical Inquiry'. I will focus on that book in the following.

In chapter three, Brümmer provides an in-depth analysis of the issue of truth (see pp. 169183; the following page numbers refer to this book). Right from the outset, he makes clear that his account of truth applies to constative assertions (see 169). After having discussed the problems of the traditional correspondence theory of truth (see 170-2), he turns to the coherence theory of truth. He holds that mathematics serves as the model for this theory since the truth or acceptability of a mathematical proposition is determined by its coherence with other propositions of the mathematical system (see 173). However, he criticizes that coherence cannot be a 'complete criterion for truth' (173). The coherence of the proposition, $p$, with other propositions does not guarantee p's truth. The reason is that the truth of those other propositions have to be fixed first before p's coherence with them can be taken to indicate p's truth. Yet, fixing the truth of those other propositions requires resources which go beyond what coherentism can deliver (see 174). Coherentism can thus not exclude the possibility of 'various mutually exclusive systems, all equally coherent with themselves. The question is, then, how are we to choose between such systems' (174).

Next, Brümmer analyses pragmatist theories of truth. He defines them as implying that a 'proposition is true if it forms part of a theory which works in practical life' (174). Yet, by way of scrutinizing the classical pragmatist accounts of Peirce, James and Dewey, Brümmer shows that all of them are found wanting: Truth cannot be identified with 'useful to believe', as James does (see 175), nor with any other pragmatist construal of what 'working' means.

Then, Brümmer suggests a characterization of truth which makes extensive use of speech 
act theory, in particular of the concept of constatives. He suggests that 'a constative is true if our possibilities for action are indeed as assured in the constative' (180). Yet, 'a constative is not some kind of representation... It is an assurance about what we are able to do. The factual situation (as determinant of our possibilities for action) is therefore a condition for the success of the constative (= assurance), not something represented or mirrored in the constative' (180-1).

\subsection{Evaluation of Brümmer's critique}

I think that Brümmer's critique is successful: In his usual straight-to-the-point manner, he identifies the core-weaknesses of the traditional theories of truth. Pragmatic theories of truth fail to distinguish between what is 'truly true' and what is useful to believe to be true. Although I am personally convinced that the classical pragmatists had more in mind than to reduce truth to utility or expediency of belief, Brümmer's point that a pragmatic theory of truth fails is well taken.

And the same goes for a coherence theory of truth. The problem with coherence is that it is a concept which regulates the relations between propositions rather than between propositions and the world. It is thus a syntactic rather than a semantic notion. Semantic concepts as that of truth are thus notoriously underdetermined by coherentist considerations.

A common response from coherence-theorists is that coherence is not a definition of truth but, rather, only a criterion for it. ${ }^{1}$ Meeting this criterion is a necessary but not a sufficient condition for truth. Yet, this response leaves the question open what needs to be added to coherence for a sufficient definition of truth. This question cannot be answered on coherentist grounds. Thus, in order to develop a definition of truth, coherentism is insufficient.

Yet, although I acknowledge that coherentist and pragmatic criteria are insufficient for the purposes of defining truth, I wonder whether they can be used differently. If they are utilized not in the context of the theory of truth proper but in a different context, can they fulfil useful functions? I will explore that possibility in the following two sections.

\section{COHERENTISM}

\subsection{Plantinga's critique of coherentist theories of justification}

Coherentism does not only come as a theory of truth but, also, as a theory of justification. ${ }^{2}$ I will investigate in the following how useful coherentist criteria are in the context of the discourse on justification. ${ }^{3}$ The guiding question will be whether the problems that crop up when using coherentist criteria in the context of the discussion on (definitions of) truth can be avoided when using them in the context of the discussion on (theories of) justification.

The standard charge against using coherentism in this context is that it is incapable of taking semantic concerns into account. For example Susan Haack has criticized it as failing to allow for a 'non-belief input': "...the coherentist's claim that empirical beliefs can be justified by nothing but relations of mutual support is as absurd as suggesting that two drunken sailors could support

1 See e.g. Puntel, Grundlagen.

2 Generally speaking, theories of justification have to do with the question under what circumstances an (appropriately situated) subject of cognition has the epistemic right ('is justified') to hold the beliefs she holds. Different from truth which is a purely semantic notion, dealing with the relationships between propositions and the world, justification thus takes the subject uttering those propositions into account as well. Yet, as will become clear below, all overly sharp distinctions between the semantic and the pragmatic dimension will be blurred since pragmatic, justification-related, considerations have semantic, truth-related, impact as well.

3 See the discussions in e.g. Nicholas Rescher, Cognitive Systematization, Laurence Bonjour, Structure, Keith Lehrer, Knowledge. 
each other by leaning back to back - when neither was standing on anything."4

Alvin Plantinga has devoted his volume 'Warrant: The Current Debate' to the critique of coherentism. His point is that it fails to relate beliefs to experience. ${ }^{5} \mathrm{He}$ illustrates this point with the help of the following example: The mountain climber Ric's belief system is frozen while being on top of a mountain. When being back in the valley, he still holds the belief system he held while being on top of the mountain. ${ }^{6}$ Plantinga's point with this example is that, although Ric's belief system is coherent, it is out of touch with reality. The coherence of a belief system does thus not guarantee that it portrays reality adequately.

\subsection{Coherentism amended by pragmatism}

Plantinga's and related critiques of coherentism have a point. Yet, let me remind you of the context we are concerned with at this point, viz. the context of justification: I think that in this context, the critique that the coherence of a belief system does not guarantee that it portrays reality adequately is not fatal. In contrast to the context of the discussion on truth, this critique should not lead us to abandon coherentism but, rather, to amend it. ${ }^{7}$ More precisely, we should amend it with pragmatism: Coherent systems of belief should be tested with the help of pragmatic criteria.

Let me explain what I mean by taking up Plantinga's example of Ric's 'frozen' belief system. I don't think that we should only ask whether it is coherent and then leave it at that, as Plantinga does. Rather, we should ask whether this coherent belief system works in the circumstances it is employed. If, for example, Ric cannot orient himself adequately with his belief system in the circumstances that he is currently in, this will speak against this system. If, to choose a crude example, Ric's frozen belief system makes him ignore the existence of the traffic in the valley and he gets run over by a car, this provides reasons to abandon this belief system in favour of another system. Thus pragmatic criteria, such as the question whether a belief system works or is successful, provide, at least, prima facie reasons for accepting or abandoning a belief system.

The pragmatic criteria suggested function as a choice-selector: They make it possible to distinguish between adequate and inadequate coherent belief systems. Thus, pragmatic criteria provide an answer to Brümmer's question on how to choose between competing coherent belief systems (see above, 1 ).

In the following section, I will flesh out this answer. In particular, I will analyse what consequences it has for the issues of realism and truth. I will use the shorter phrase 'pragmatic justifications' rather than 'coherently pragmatic justifications'. Yet, I presuppose that the pragmatic justifications suggested are applied for choosing between coherent (rather than incoherent) systems of belief.

\section{FLESHING OUT PRAGMATIC JUSTIFICATIONS}

\subsection{Pragmatic justifications and Realism}

The kind of realism that can be legitimated by pragmatic justifications is an en bloc realism or holism. Only systems of beliefs rather than individual beliefs can be justified along the pragmatic lines suggested. This has to do with the fact that pragmatic criteria apply only to such systems. Only systems of coherent beliefs can work or fail to work, not individual beliefs.

4 Haack, Evidence, pp. 27-8.

5 See Plantinga, Warrant, pp. 80-3.

6 See Plantinga, Warrant, p. 82.

7 In particular, when we consider the problems that coherentism's alternative, foundationalism, harbors (for a critique of foundationalism, see e.g. Dirk-Martin Grube, Religious Experience, pp. 41-50). 
Let me give an example: Imagine we have a computer model of the Atlantic Ocean into which we feed all the relevant data, the water depths, differences in temperature and the like. If this model generates something like the Gulfstream, then we have reasons to assume that this model allows for an adequate orientation in reality. We have, at least, prima facie reasons to assume that it has captured some features of the world adequately. Assuming the contrary, viz. that it has failed to capture those features adequately, would leave us with the problem of having to explain how it can predict the existence of the Gulfstream.

Yet, the judgment that it has captured some features of reality adequately refers to the model as a whole. It does not necessarily imply that each and every individual bit of data from which this model is composed captures reality appropriately. Although it is probably inconceivable to assume that all the relevant data is off the mark, it is well conceivable that some data is. There is thus no guarantee that all sub-beliefs within a working belief system portray reality adequately. In all likelihood, they are not all beside the mark but it cannot be excluded that some sub-beliefs are.

Let me clarify that point with the help of another image: Think of a fishing-net. After having laid it out in the water, you are capable of telling whether you have caught something or not. But you cannot tell with which individual mesh you made the catch.

The same holds for the pragmatic justifications suggested: Applying pragmatic criteria makes it possible to tell whether the catch is successful. It provides prima facie justifications for holding that a coherent belief system portrays reality or, rather, particular aspects of it, adequately. Yet, it is impossible to tell which individual sub-belief is successful and which is not. All that can be held is that the system as a whole, i.e. the individual sub-beliefs being connected the way they are connected, works. Thus, the kind of realism emerging form the suggestion to test coherent belief systems with the help of pragmatic criteria is a holist kind.

Obviously, this holism does not exclude the possibility of making educated guesses. For example, it is not highly likely that core sub-beliefs of a working belief system are off the mark. Given that the system as a whole works, chances are that its core beliefs are not completely wrong. Above all, it is unlikely that all core beliefs in a working belief system portray reality inadequately - otherwise it would be difficult to explain why the system still works. Yet, it is well conceivable that some sub-beliefs belonging to the periphery of the belief system portray reality inadequately. It is conceivable that a belief system can harbour mistaken sub-beliefs and yet continue to work.

\subsection{Pragmatic justifications and Truth}

The epistemic claims that can be generated by pragmatic justifications differ from truth-claims proper. There are, at least, two reasons for this:

The first is a principled reason: Truth is a predicate pertaining to propositions, i.e. to individual beliefs formulated in statements. Only individual statements or comparable utterances ${ }^{8}$ can be true or not. Yet, pragmatic justifications in the sense specified pertain to systems of beliefs rather than to individual beliefs, as has been demonstrated above (see 3.A.). Thus, the epistemic merits which can be generated from pragmatic justifications pertain to those systems of beliefs rather than to the individual beliefs they are composed of.

Nor can those epistemic merits be translated into truth-claims proper: That a belief system possesses the merit 'success' cannot be translated into ascribing the merit 'truth' to its subbeliefs. The reason for this untranslatability were provided above (see 3.A.): It cannot be excluded that a successful belief system contains false sub-beliefs.

There is also a second reason why we should be cautious to use the truth predicate for

8 See 1, Brümmer's considerations on 'constatives'. 
identifying the epistemic merits which can be generated by pragmatic justifications. This reason has to do with the nature of the argumentation provided: It is a relative one rather than an absolute one. That is to say, given the pragmatic justification suggested, all we can say is that belief system A is more likely to capture reality than belief system B. If A works and B does not, we have prima facie better reasons to assume that $A$ captures reality adequately than to assume that B does. The argument is thus a relative one: We weigh A's chances against B's and come to conclusions based upon this comparison. Yet, such a relative procedure is different from an absolutist one according to which truth can be fixed definitely.

Of course, we can decide to label the epistemic merits which can be generated in this relative fashion 'truth'. Yet, this would be a deviation from the philosophical tradition in which, at least, in my understanding, the truth predicate implies more than only relative epistemic merits. If $\mathrm{x}$ is predicated to be 'true', then this means traditionally more than suggesting that, in comparison to $y, x$ is in some sense epistemically better off. It means rather that $x$ is absolutely certain.

For those two reasons, I suggest that the epistemic merits which can be generated from pragmatic justifications should not be identified with truth proper but with logically weaker values.

\subsection{Pragmatic justifications between 'Truth' and 'truth'}

My suggestion to construe the epistemic merits generated by pragmatic justifications logically weaker than truth proper must, however, be sharply distinguished from postmodernist constructions of truth. It is not in line with, say, Richard Rorty's notorious trivializations of the concept of truth. It does not reduce truth to '...a compliment paid to the beliefs which we think so well justified that, for the moment further justification is not needed. ${ }^{9}$ Trivializations of this sort undermine the basic rationale upon which the quest for truth is grounded whereas my suggestion does not.

Let me explain what I mean: The traditional quest for truth is rooted in my view in a lifeworldly basis. That is, it is not l'art pour l'art but is rooted in basic human needs. For lack of better terms, I summarize those needs here as a basic necessity to orient ourselves adequately in our environment. And orienting ourselves adequately is at the same time the basis for taking proper action. Thus, the traditional quest for truth has its roots in this necessity to orient ourselves adequately in our life-world and, as a consequence, to be able to take proper action.

This is the point Rorty's and comparable trivializations of the issue of truth overlook. To put it bluntly: If the concept of truth had no more implications than the terms 'here' and 'there', as Rorty suggests ${ }^{10}$, then we would need some other category which does justice to the basic human need for proper orientation.

I emphasize this point that strongly not only because some philosophical agent provocateurs overlook it but, also, because the more serious philosophical work on the notion of truth is in jeopardy of neglecting it. In particular, the philosophical discussions on the definition of truth are often so immersed in purely technical concerns that they lose sight of the basic rationale underlying the quest for truth. I think that whatever victories can be gained by defining truth as being redundant ${ }^{11}$, as being a purely syntactic concept, etc. are Pyrrhic victories if they cannot accommodate this rationale.

Suggesting logically weaker terms than truth proper, as I did above, is, however, faithful to this basic rationale. It is directed against a particular way of dealing with this rationale, viz. against the traditional focus on individual beliefs or sentences as bearers of truth. Yet, what is

9 Rorty, Solidarity, p. 24.

10 Rorty, Solidarity, p. 23.

11 See Brümmer, Theology, pp. 187-81. 
lost on the level of individual beliefs is re-gained on the level of systems of beliefs: According to the suggestion made above, the success of those systems provides us, at least, with prima facie reasons to assume that they have captured some aspects of reality adequately. Thus, the basic rationale lying behind the traditional quest for truth, viz. its function to orient ourselves adequately in our environment, is well preserved.

The way it is preserved differs obviously from the classical philosophical tradition. Its point is not to approximate Truth (capital T) in the way it was supposed to be approximated from the Greek philosophical tradition up to Descartes. Pragmatic justifications as recommended above do not get us to the unchangeable Ideas behind empirical reality nor to the indubitable foundation of all thinking. Yet, they allow us to orient ourselves adequately in our life-world and thus provide proper reasons for action. This, I take it, is sufficient for us humans as principally limited and fallible beings.

A convenient way to characterize the intention behind introducing pragmatic criteria is to situate it between Truth and truth: It falls short of the intention behind the traditional quest for Truth, the search for absolute certainty. Yet, it goes beyond the intention to trivialize truth a la Rorty. It does not sacrifice the basic rationale underlying the human quest for truth.

\subsection{Ontological presuppositions of pragmatic justifications}

There is one issue which is easily overlooked and deserves separate mention for that reason: The pragmatic justifications suggested are not completely neutral with regard to ontology. Translating the success of a system of beliefs into holistically construed realist assumptions presupposes certain basic ontological assumptions about the world. Put differently, translating the upshot of pragmatic justifications into semantic claims is not completely free of all ontological presuppositions.

For example, translating the success of the above mentioned computer model of the Atlantic Ocean - which is capable of predicting the existence of the Gulfstream (see above, 3.A.) - into the claim that it has probably captured some aspects of reality adequately works only if we presuppose certain assumptions about the basic structure of reality. One such assumption is that it is not malleable in whichever way we wish. Because if reality would be malleable in such a way, nothing semantically interesting would follow from the model's predictive success. If this were the case, we would not be entitled to prefer this model over a competing model with respect to its capacity to portray reality adequately. The same holds for the assumption that there is a multiplicity or even endless variety of worlds. If there would be such a variety, the fact that this model can make successful predictions could not be translated into the claim that it has captured some aspects of reality adequately. The reason is simply that there is no such thing as reality in the singular which can be captured adequately. There are only a multiplicity of realities.

In sum, the pragmatic justifications suggested presuppose certain basic ontological assumptions, e.g. those which exclude the idea of a complete malleability of reality or the existence of an endless variety of worlds.

The reason that I bring up those examples is not that I think them to be very convincing. As a matter of fact, I think they are philosophical fancies far off the mark. Yet, they are important in order to appreciate my argument and the assumptions upon which it is based.

The fact that my argument presupposes certain basic ontological assumptions has consequences for its applicability: It is not the antidote to the radical sceptic that e.g. Descartes is out to refute. It does not demonstrate the logical impossibility of scepticism. Logically, nothing speaks against suggesting that reality is completely malleable, that there is an endless variety of worlds, or whatever fancies philosophers may come up with. Yet, the argument succeeds in raising the stakes for the sceptic: She must assume those ontological assumptions (or related 
fancies) in order to maintain her case for scepticism. The argument provided thus does not demonstrate the logical impossibility but, rather, the high degree of implausibility of scepticism.

In my view, this is all we need at this late point in the history of philosophy. Trying to achieve more, trying to provide anti-sceptical arguments beyond every possible doubt, often bears sour fruits. This, I take it, is the lesson to be learnt from the history of philosophy: The anti-sceptical quest in the name of absolute certainty is a philosophical dream which all too often turns into a nightmare. The curious result of the Cartesian and related quests for certainty beyond every possible doubt is that it has come to nourish that which it was out to rebut, viz. scepticism.

As heirs of this tradition, we should learn from its mistakes. Our ambitions should be more modest: We should not be after absolute certainty. Rather, we should moderate our goals. We should be only after whatever amount of certainty is sufficient to orient ourselves adequately in our live-world. Insofar as we can get this amount of certainty out of pragmatic justifications, we should be satisfied with them. They provide sufficient reasons for proper action and that is all we need.

\section{RELATING PRAGMATIC JUSTIFICATIONS TO BRÜMMER'S VIEW}

In this final section, I will relate my suggestions to Brümmer's views on the issue. As will be remembered, I shared Brümmer's rejection of coherentist and pragmatic definitions of truth. Yet, I asked whether coherentist and pragmatic criteria can be used differently than as criteria for the purposes of defining truth. That lead me to use coherent systems of beliefs as a vantage point for my theorizing. I acknowledged the force of Brümmer's point that there can be a variety of different, even incompatible coherent belief-systems. Yet, I did not use that as a knockdown argument against coherentism but suggested that it should be amended with pragmatic justifications: Pragmatic criteria allow us to differentiate between the competing coherent systems so that we can maintain some form of realism, viz. a holist form of realism.

How does this holism legitimated by pragmatic justifications relate to Brümmer's views? In chapter 18 of 'Theology' (pp. 225-48; the following page numbers refer to this book), Brümmer analyses the systematic linkages between the concepts of 'existence', 'facts', and 'reality'. The upshot of that analysis is a particular stance on the issues that are commonly discussed under the heading 'realism'. ${ }^{12}$ This stance is characterized by understanding the 'real world' (236) as consisting of 'the total acting-situation in which we find ourselves, the complete set of determinations of our possibilities for action' (236). Brümmer thus weaves those concepts, hence, the question of realism, closely together with a theory of (the possibilities for) action. According to him, saying that something exists is tantamount to 'giving my hearer the assurance that there is one (or more) situation(s) within the real world in which that "something" makes a difference to what we can and cannot do' (236). In short, Brümmer answers questions revolving around the issue of realism on action-theoretical grounds (in the broad sense of the word).

I wonder to what extent this answer differs from my own suggestion worked out above. Obviously, there are differences in the philosophical vantage points: Brümmer's vantage point is the speech-act theory. I do not reject it but grant it a less prominent role than Brümmer does. In my approach, pragmatism plays the crucial role. Yet, do those differences in philosophical vantage points truly lead to different net-results? Or do those results differ less than one may expect? Do the different vantage points lead us to choose different paths to walk along but our final destination is similar?

For example, Brümmer answers the question on why we use the real-world language for the

12 Brümmer, however, does not use the term 'realism' extensively because he finds the whole 'conflict between realists... and subjective idealists founded on a mistaken formulation of the problem' (234-5). 
purposes of solving problems of existence as follows: 'Our choice of the real-world language is necessitated by the practical needs of human life on earth' (236). This sounds suspiciously similar to what was identified above (see 3.C.) as the basic human needs in which the traditional quest for truth is rooted.

It can be retorted now that, for Brümmer, the subject and her (possibilities for) actions are crucial whereas my suggestions do not focus on the subject that strongly: The payoff of the pragmatic justifications sketched above is not cashed in in terms of the subject and her actions but, rather, in terms of a specific way of construing the relation between language and world. This is admittedly a non-orthodox way of construing this relation in that it focuses neither on the issues of reference nor on truth, as orthodox constructions do. That is, it focuses neither on the relation between word and world nor on that between sentences and the world. Rather, it focuses on the relation between systems of sentences or beliefs and reality. Yet, so the contender may summarize her point, although non-orthodox, it is nevertheless a semantic approach (in the broad sense of the word). Yet, Brümmer attempts to overcome semantic approaches with his emphasis upon the subject's actions.

Although this is true in theory, I wonder how much difference it makes in practice. Take e.g. Brümmer's solution to the problem of past facts: He acknowledges that it is a challenge to his account that questions of fact can be raised which are located in the past. They do not make a difference to our current (possibilities for) actions, as his action-centred account would require. His answer to that challenge is to introduce logical possibility: Questions of fact do not have to make a difference to our current possibilities for action. Rather, they must make a difference 'in cases where it is logically possible that someone (no matter who) has been/is/will be in a position where the state of affairs in question would make a difference to his possibilities for action' (245). Brümmer specifies his action-centred account here so as to include potential actors in the past, present and future. This is obviously a very generous account of action which entails a broad notion of the subject performing those actions: It includes not only present but also past and future, thus imaginary, subjects. Given such a wide characterization of the subject's actions, the potential differences between an action-thus-subject-centred account as Brümmer's and a semantically-oriented account as I suggest are minimized.

I am very curious how Brümmer himself would characterize the relation between his own account and (broadly) semantic accounts, such as the one provided above. ${ }^{13}$

\section{BIBLIOGRAPHY}

Bonjour, Laurence, The Structure of Empirical Knowledge, Cambridge (Mass.), Harvard University Press, 1985.

Brümmer, Vincent, Theology and Philosophical Inquiry: An Introduction, London/Basingstoke, MacMillan, 1981.

Grube, Dirk-Martin, Religious Experience after the Demise of Foundationalism, in: Religious Studies 31 (1995), pp. 37-52.

Haack, Susan, Evidence and Inquiry. Towards Reconstruction in Epistemology, Oxford, Blackwell, 1993. Lehrer, Keith, Theory of Knowledge, Boulder, Westview Press, 1990.

Plantinga, Alvin, Warrant. The Current Debate, Oxford, Oxford University Press, 1993.

13 For space reasons, I cannot delve into the consequences both accounts have for religious issues. Therefore, I restrict myself here to mentioning in passing that I share Brümmer's concern for the defense of religion. In a similar way as his approach creates space for religious issues (see 249-90), the pragmatically justified holism favored here creates space as well. For example, the emphasis upon beliefsystems rather than individual beliefs allows for testing religious belief systems in a fashion which is more sympathetic with them than traditional logical-positivist or Popperian approaches are with their emphasis upon the testing of individual beliefs. 
http://ngtt.journals.ac.za

Puntel, Lorenz B., Grundlagen einer Theorie der Wahrheit, Berlin, De Gruyter, 1990.

Rescher, Nicholas, Cognitive Systematization. A Systems-Theoretic Approach to a Coherentist Theory of Knowledge, Oxford, Blackwell, 1979.

Rorty, Richard, Solidarity or Objectivity? In: Rorty (ed.), Objectivity, Relativism, and Truth, Cambridge et al., Cambridge University Press, 1991. 